\title{
Perampanel for tonic-clonic seizures in idiopathic generalized epilepsy
}

\section{A randomized trial}

\section{OPEN D国}

Jacqueline A. French, MD Gregory L. Krauss, MD

Robert T. Wechsler, MD, $\mathrm{PhD}$

Xue-Feng Wang, MD

Bree DiVentura, MBA

Christian Brandt, MD

Eugen Trinka, MD, MSc

Terence J. O’Brien, MD, BS

Antonio Laurenza, MD

Anna Patten, PhD

Francesco Bibbiani, MD

Correspondence to

Dr. French:

jacqueline.french@nyumc.org

Supplemental data at Neurology.org

\section{ABSTRACT}

Objective: To assess efficacy and safety of adjunctive perampanel in patients with drug-resistant, primary generalized tonic-clonic (PGTC) seizures in idiopathic generalized epilepsy (IGE).

Methods: In this multicenter, double-blind study (ClinicalTrials.gov identifier: NCT01393743; funded by Eisai Inc.), patients 12 years or older with PGTC seizures and IGE were randomized to placebo or perampanel during a 4-week titration period (perampanel uptitrated from 2 to $8 \mathrm{mg} / \mathrm{d}$, or highest tolerated dose) and 13-week maintenance period. The primary endpoint was percent change in PGTC seizure frequency per 28 days (titration plus maintenance vs baseline). The key secondary endpoint (primary endpoint for European Union registration) was 50\% PGTC seizure responder rate (patients achieving $\geq 50 \%$ reduction in PGTC seizure frequency; maintenance vs baseline). Treatment-emergent adverse events were monitored.

Results: Of 164 randomized patients, 162 comprised the full analysis set (placebo, 81; perampanel, 81). Compared with placebo, perampanel conferred a greater median percent change in PGTC seizure frequency per 28 days (-38.4\% vs $-76.5 \%$; $p<0.0001$ ) and greater 50\% PGTC seizure responder rate (39.5\% vs $64.2 \% ; p=0.0019)$. During maintenance, $12.3 \%$ of placebotreated patients and $30.9 \%$ of perampanel-treated patients achieved PGTC seizure freedom. For the safety analysis (placebo, 82; perampanel, 81), the most frequent treatment-emergent adverse events with perampanel were dizziness (32.1\%) and fatigue (14.8\%).

Conclusions: Adjunctive perampanel was well tolerated and improved control of drug-resistant PGTC seizures in patients with IGE.

Classification of evidence: This study provides Class I evidence that adjunctive perampanel reduces PGTC seizure frequency, compared with placebo, in patients with drug-resistant PGTC seizures in IGE. Neurology ${ }^{\circledR} 2015 ; 85: 950-957$

\section{GLOSSARY}

$\mathbf{A E}=$ adverse event; $\mathbf{A E D}=$ antiepileptic drug; $\mathbf{A M P A}=\alpha$-amino-3-hydroxy-5-methyl-4-isoxazole propionic acid; $\mathbf{C G I - C}=$ Clinical Global Impression of Change; IGE = idiopathic generalized epilepsy; ILAE = International League Against Epilepsy; PGTC $=$ primary generalized tonic-clonic; SMQ = Standardized Medical Dictionary for Regulatory Activities query; TEAE = treatment-emergent adverse event.

Few antiepileptic drugs (AEDs) are licensed to treat primary generalized tonic-clonic (PGTC) seizures. ${ }^{1}$ One therapeutic target yet to be explored in this setting is the postsynaptic $\alpha$-amino-3-hydroxy-5-methyl-4-isoxazole propionic acid (AMPA) glutamate receptor. This receptor has been considered a rational target for epilepsy treatments because it mediates most fast excitatory synaptic transmission in the CNS and has been implicated in multiple disorders characterized by neuronal overexcitation. ${ }^{2}$ Antagonism of AMPA receptors has been associated

\footnotetext{
From NYU Comprehensive Epilepsy Center (J.A.F.), New York, NY; Johns Hopkins Hospital (G.L.K.), Baltimore, MD; Idaho Comprehensive Epilepsy Center (R.T.W.), Boise, ID; The First Affiliated Hospital of Chongqing Medical University (X.-F.W.), China; The Epilepsy Study Consortium (B.D.), Herndon, VA; Bethel Epilepsy Center (C.B.), Bielefeld, Germany; Department of Neurology (E.T.), CDK, Paracelsus Medical University and Centre for Cognitive Neuroscience, Salzburg, Austria; Departments of Medicine and Neurology (T.J.O.), The Royal Melbourne Hospital, The University of Melbourne, Australia; Eisai Neuroscience Product Creation Unit (A.L., F.B.), Woodcliff Lake, NJ; and Department of Biostatistics (A.P.), Eisai, Hatfield, UK.

Go to Neurology.org for full disclosures. Funding information and disclosures deemed relevant by the authors, if any, are provided at the end of the article. The article processing charge was paid for by Eisai Inc.

This is an open access article distributed under the terms of the Creative Commons Attribution-NonCommercial-NoDerivatives License 4.0 (CC BY-NC-ND), which permits downloading and sharing the work provided it is properly cited. The work cannot be changed in any way or used commercially.
} 
with antiseizure effects in amygdala-kindled rats, potentially indicating clinical efficacy in primary generalized seizure types. ${ }^{3-5}$

The noncompetitive AMPA receptor antagonist, perampanel, has been evaluated in 3 randomized, double-blind, placebo-controlled trials in patients with partial-onset seizures, with or without secondary generalization, despite receiving 1 to 3 AEDs. Significant reductions in the frequency of all partial-onset seizures, and in the frequency of complex partial plus secondarily generalized seizures and secondarily generalized seizures only, were observed with adjunctive perampanel at daily doses of 4 to 12 mg. ${ }^{6-9}$ Consequently, perampanel is now approved in more than 40 countries worldwide for adjunctive treatment of partial-onset seizures, with or without secondarily generalized seizures, in patients with epilepsy aged 12 years and older (18 years and older in Canada). ${ }^{10,11}$ The indication for perampanel in the United States and Europe has recently been expanded to include the adjunctive treatment of PGTC seizures in patients with idiopathic generalized epilepsy [IGE] aged $\geq 12$ years.

It is unknown whether efficacy against secondarily generalized seizures in focal epilepsies translates to efficacy against PGTC seizures in IGE. This study assessed the efficacy and safety of adjunctive perampanel in patients with drugresistant PGTC seizures associated with IGE.

METHODS Classification of evidence. Primary research question: Does adjunctive perampanel provide an effective option for treatment of drug-resistant PGTC seizures in adults and adolescents with IGE? This interventional study provides Class I evidence that adjunctive perampanel $8 \mathrm{mg}$ significantly reduces PGTC seizure frequency and improves 50\% PGTC seizure responder rates in patients aged 12 years and older with drug-resistant PGTC seizures and IGE.

Standard protocol approvals, registrations, and patient consents. This trial (Eisai Inc. protocol: E2007-G000-332; ClinicalTrials.gov identifier: NCT01393743) was conducted at 78 sites in 16 countries (Australia, Austria, China, Czech Republic, France, Germany, Greece, India, Israel, Japan, Latvia, Lithuania, Poland, Serbia, South Korea, United States). It was performed in accordance with the Declaration of Helsinki, Good Clinical Practice ICH-E6 Guideline CPMP/ICH/135/95, European Good Clinical Practice Directive 2005/28/EC and Clinical Trial Directive 2001/ 20/EC, and US Code of Federal Regulations Part 21. Trial protocol, amendments, and informed consent were reviewed by national regulatory authorities in each country and independent ethics committees or institutional review boards for each site. Before participation, all patients gave written informed consent.
Patients. Patients were aged 12 years and older and diagnosed with PGTC seizures and IGE according to the 1981 International League Against Epilepsy (ILAE) classification of epileptic seizures $^{12}$ and the 1989 ILAE classification of epilepsies and epileptic syndromes, ${ }^{13}$ which were in use when this study was designed. The term "idiopathic" (in IGE) is synonymous with "genetic" in the ILAE 2010 revised classification of seizures and epilepsy. ${ }^{14}$

All diagnoses were confirmed by independent reviewers from the Epilepsy Study Consortium based on age at onset, EEG data, IQ, MRI, and seizure descriptions (appendix e-1 on the Neurology ${ }^{\circledR}$ Web site at Neurology.org). Patients could be excluded because of insufficient information to confirm an IGE diagnosis (e.g., if the patient had only generalized tonic-clonic seizures and a normal EEG) or incorrect IGE diagnosis (e.g., slow spike-wave, developmental delay, or age at onset within first year of life). If a patient was considered ineligible, the information was sent to a second independent reviewer. If both reviewers were in agreement, the patient failed screening. Patients were also required to have $\geq 3$ PGTC seizures during baseline and be taking stable doses of 1 to 3 approved AEDs.

Trial design. This was a multicenter, randomized, double-blind, placebo-controlled, parallel-group study. A prerandomization phase comprised screening ( $\leq 4$ weeks) and baseline ( 4 or 8 weeks, depending on the accuracy of diary-documented seizures during screening). Eligible patients were randomized (1:1) using an interactive voice response system to receive placebo or oral perampanel, stratified by country. A subsequent randomization phase comprised titration (weeks 1-4), maintenance (weeks 5-17), and follow-up (weeks 18-21; only patients not entering an extension phase). During randomization, patients and all personnel, including investigators, site personnel, and sponsor staff, were blinded to treatment. Study drugs were packaged and labeled to be indistinguishable between treatment groups.

During titration, patients in the perampanel group received an initial daily dose of $2 \mathrm{mg}$, before uptitration in weekly 2-mg increments to the targeted daily dose of $8 \mathrm{mg}$ or the highest tolerated dose (whichever was lower). Patients entered the maintenance period at the last dose achieved during titration. Dose adjustment during the maintenance period was not recommended; however, according to the investigator's clinical judgment, patients with inadequate seizure control could have their dose increased by one 2 -mg increment (up to a maximum daily dose of $8 \mathrm{mg}$ ) and patients who experienced intolerable adverse events (AEs) could have their dose decreased by one 2-mg increment.

Efficacy assessments. Seizure counts were recorded in patient diaries. The primary efficacy endpoint was the percent change in PGTC seizure frequency per 28 days (titration plus maintenance vs baseline). The key secondary endpoint was 50\% PGTC seizure responder rate (percentage of patients achieving $\geq 50 \%$ reduction in PGTC seizure frequency during maintenance vs baseline; last observation carried forward). However, 50\% PGTC seizure responder rate was designated as the primary endpoint for the purpose of registration in the European Union, according to European Union guidelines.

Percent change in seizure frequency and 50\% responder rate for all seizures were also evaluated as secondary efficacy endpoints. Exploratory efficacy endpoints included rates of freedom from PGTC seizures and all seizures during maintenance, and investigator-assessed Clinical Global Impression of Change (CGI-C) (assessment of clinical status throughout the 4 weeks before week 12, rated on a scale from 1 [very much improved] to 7 [very much worse]; last observation carried forward).

Safety assessments. Safety assessments included monitoring all treatment-emergent AEs (TEAEs), treatment discontinuations, 
clinical laboratory test results (chemistry, hematology, and urinalysis), and vital signs.

A combination of broad and narrow Standardized Medical Dictionary for Regulatory Activities queries (SMQs) were used to evaluate events in prespecified categories of special interest: abuse potential, accident/injury, alertness and cognition, cardiac and ECG TEAEs, drug-related hepatic disorder abnormalities, fall, hostility/ aggression (a narrow SMQ only was also applied), psychosis and psychotic disorders (a narrow SMQ only was also applied), rash, status epilepticus/convulsions, and suicidal ideation and behavior.

Statistical analyses. The full analysis set included all randomized patients who received at least one dose of study drug and had any postbaseline seizure frequency data. The safety analysis set included all randomized patients who received at least one dose of study drug and had at least one postbaseline safety assessment.

For the analysis of PGTC seizure frequency, baseline and percent change data were rank-transformed separately. Analysis of covariance was conducted on the rank-transformed percent change data with treatment and pooled countries as factors and the ranked baseline PGTC seizure frequency as a covariate. Treatment difference was estimated using the Hodges-Lehmann estimator and associated $95 \%$ confidence intervals. Treatment differences for 50\% PGTC seizure responder rates and CGI-C scores were analyzed using the Cochran-Mantel-Haenszel test, stratified by pooled country.

For percent change in PGTC seizure frequency, assuming a common SD of $60 \%$, a sample size of 82 patients per treatment group provided $>85 \%$ power to detect a $30 \%$ difference based on a Wilcoxon rank sum test with a 0.052 -sided significance level. For $50 \%$ PGTC seizure responder rate, assuming a rate of $35 \%$ for the placebo group and $57 \%$ for the perampanel group, a sample size of 82 patients per group had $>80 \%$ power to detect a between-group difference in the proportion of responders based on a 2-group $\chi^{2}$ test with a 0.052 -sided significance level.
RESULTS Patient allocation and demographics. The first patient was enrolled in July 2011, and the last patient visit occurred in May 2014. Of 307 screened patients (figure 1), 143 were not included, mainly because of failure to meet inclusion criteria ( $\mathrm{n}=$ 117, of which 70 failed based on review by the Epilepsy Study Consortium, either because of misdiagnosis of IGE [ $\mathrm{n}=35]$ or insufficient information to confirm diagnosis $[\mathrm{n}=35])$. The remaining $164 \mathrm{pa}-$ tients were randomized (placebo $\mathrm{n}=82$; perampanel $\mathrm{n}=82$ ). There were 163 patients in the safety analysis set (placebo $\mathrm{n}=82$; perampanel $\mathrm{n}=81$ ) and 162 in the full analysis set (placebo $\mathrm{n}=81$; perampanel $\mathrm{n}=$ 81). The proportion of patients who completed the study was similar in the placebo and perampanel groups ( $87.8 \%$ vs $84.0 \%$, respectively). A median daily dose of $8 \mathrm{mg}$ was achieved by 65 patients (80.2\%) treated with perampanel; the remaining 16 patients (19.8\%) achieved a median daily dose of 4 to $<8 \mathrm{mg}$.

The placebo and perampanel groups were comparable in baseline patient demographics and epilepsyspecific medical history (table 1). Overall, the most frequently used concomitant AEDs at baseline were lamotrigine (64/163 patients; 39.3\%), valproic acid $(55 / 163 ; 33.7 \%)$, levetiracetam $(51 / 163 ; 31.3 \%)$, and topiramate $(25 / 163 ; 15.3 \%)$.

Efficacy. During prerandomization, median PGTC seizure frequency per 28 days (range) was 2.5 (1.011.7) for placebo and 2.6 (1.4-18.5) for perampanel; during the randomization phase, these frequencies dropped to $1.6(0.0-39.1)$ and $0.7(0.0-22.8)$,

\section{Figure 1 Patient disposition}

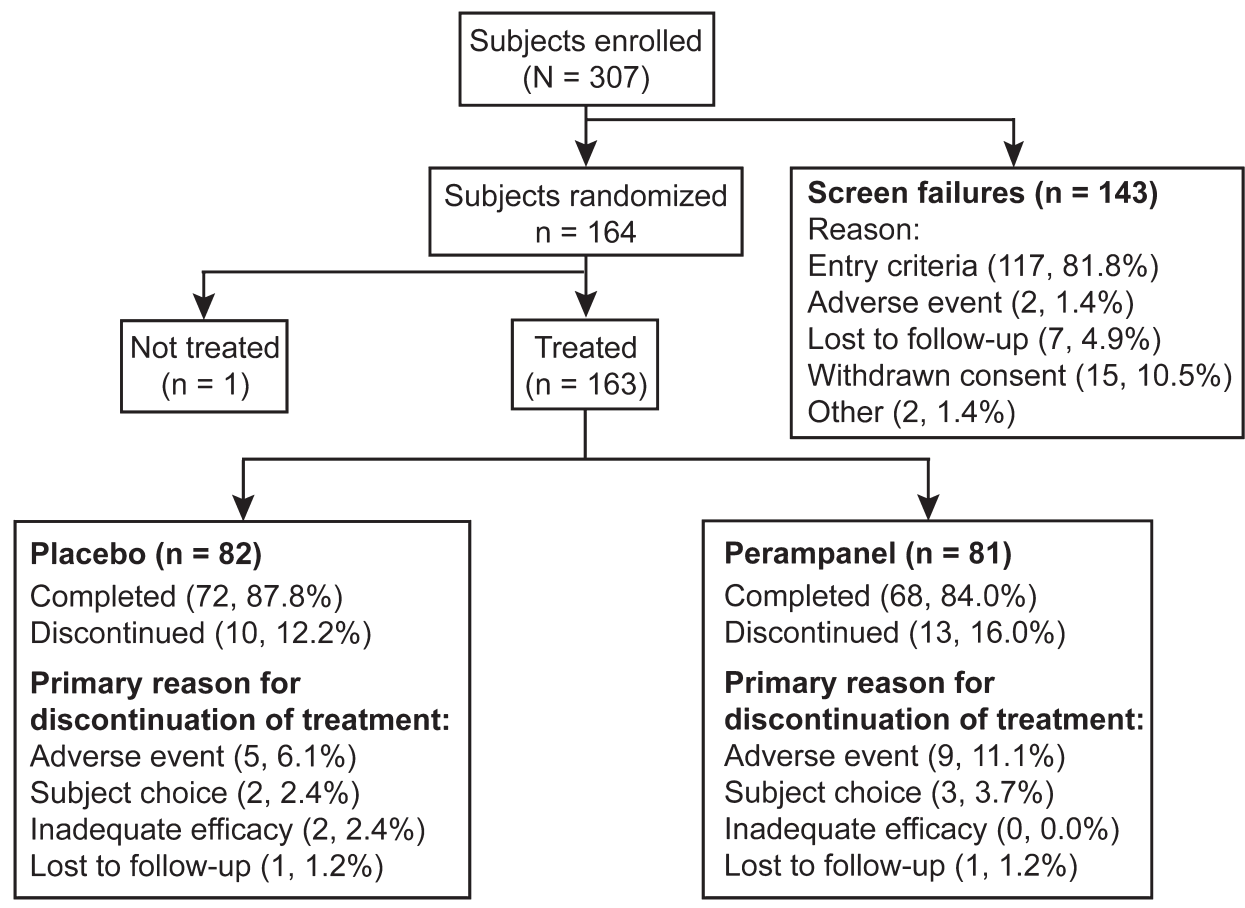




\begin{tabular}{|c|c|c|c|}
\hline \multirow[t]{2}{*}{ Baseline patient den } & \multirow[t]{2}{*}{ nd epilepsy- } & \multirow[t]{2}{*}{ pecific med } & \multirow[t]{2}{*}{ cal history } \\
\hline & & & \\
\hline \multicolumn{4}{|l|}{ Demographics; full analysis set } \\
\hline $\mathbf{N}$ & 81 & 81 & 162 \\
\hline Mean age, y (SD) & 29.5 (12.2) & $27.3(10.5)$ & $28.4(11.4)$ \\
\hline Female, n (\%) & 45 (55.6) & $46(56.8)$ & $91(56.2)$ \\
\hline \multicolumn{4}{|l|}{ Race, n (\%) } \\
\hline White & $43(53.1)$ & $44(54.3)$ & $87(53.7)$ \\
\hline Black or African American & $3(3.7)$ & $1(1.2)$ & $4(2.5)$ \\
\hline Japanese & $6(7.4)$ & $5(6.2)$ & $11(6.8)$ \\
\hline Chinese & 18 (22.2) & 18 (22.2) & 36 (22.2) \\
\hline Other Asian & $10(12.3)$ & $11(13.6)$ & $21(13.0)$ \\
\hline Other & $1(1.2)$ & $2(2.5)$ & $3(1.9)$ \\
\hline \multicolumn{4}{|l|}{$\begin{array}{l}\text { Epilepsy-specific medical history; safety } \\
\text { analysis set }\end{array}$} \\
\hline $\mathbf{N}$ & 82 & 81 & 163 \\
\hline Mean time since diagnosis, y (SD) & $18.6(12.6)$ & $15.7(10.8)$ & $17.2(11.8)$ \\
\hline \multicolumn{4}{|l|}{ Seizure type, n (\%) } \\
\hline Tonic-clonic & $82(100.0)$ & $81(100.0)$ & $163(100.0)$ \\
\hline Myoclonic & $33(40.2)$ & 32 (39.5) & 65 (39.9) \\
\hline Absence & $41(50.0)$ & $42(51.9)$ & 83 (50.9) \\
\hline Clonic & 1 (1.2) & $0(0.0)$ & $1(0.6)$ \\
\hline Tonic & $2(2.4)$ & $0(0.0)$ & $2(1.2)$ \\
\hline Atonic & $1(1.2)$ & $0(0.0)$ & $1(0.6)$ \\
\hline \multicolumn{4}{|c|}{ No. of background AEDs at baseline, $n(\%)$} \\
\hline 1 & 29 (35.4) & 26 (32.1) & 55 (33.7) \\
\hline 2 & 36 (43.9) & 39 (48.1) & 75 (46.0) \\
\hline 3 & 16 (19.5) & 16 (19.8) & 32 (19.6) \\
\hline 4 & 1 (1.2) & $0(0.0)$ & $1(0.6)$ \\
\hline
\end{tabular}

Abbreviation: $\mathrm{AED}=$ antiepileptic drug.

${ }^{\text {a }}$ Note that a patient may have $\geq 1$ seizure type.

respectively. Overall, compared with placebo, perampanel conferred a greater median percent change in PGTC seizure frequency per 28 days $(-38.4 \%$ vs $-76.5 \% ; p<0.0001)$ and was associated with a greater $50 \%$ PGTC seizure responder rate $(39.5 \%$ vs $64.2 \% ; p=0.0019$; figure 2 ).

Compared with placebo, there was also a greater median percent change in the frequency of all seizures per 28 days in the perampanel group $(-22.9$ vs -43.4; $p=0.0018)$. During the maintenance period, $12.3 \%$ of placebo-treated patients and $30.9 \%$ of perampanel-treated patients achieved freedom from PGTC seizures; $4.9 \%$ of placebo-treated patients and $23.5 \%$ of perampanel-treated patients achieved freedom from all seizures.

At week 12, 32.9\% of placebo-treated patients and $39.2 \%$ of perampanel-treated patients were considered "much" or "very much" improved according to CGI-C scores $(p=0.5639)$.
Figure 2 Median percent change in PGTC seizure frequency and $50 \%$ PGTC seizure responder rates
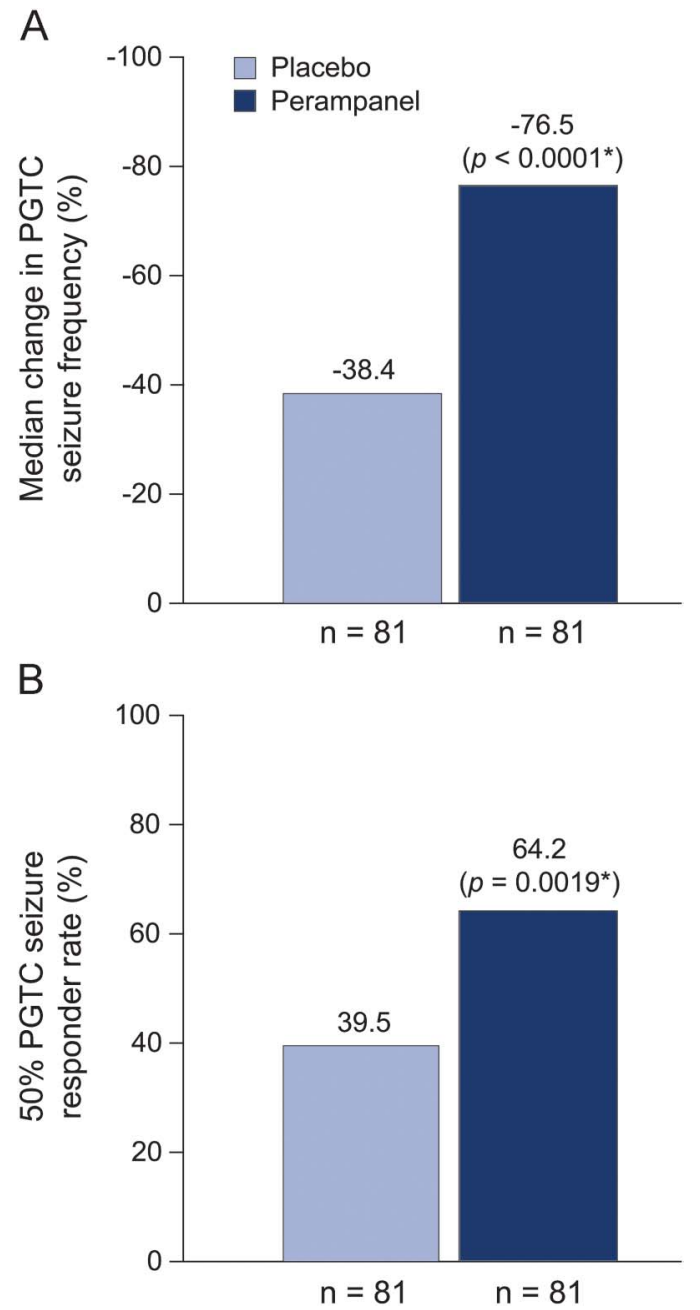

(A) Median percent change in seizure frequency per 28 days (full analysis set). (B) Fifty percent PGTC seizure responder rates (percentage of patients achieving $\geq 50 \%$ reduction in PGTC seizure frequency during maintenance vs baseline; full analysis set). *Versus placebo. PGTC = primary generalized tonic-clonic.

Safety. TEAEs were reported in 59 placebo-treated patients $(72.0 \%)$ and 67 perampanel-treated patients $(82.7 \%)$, with the majority of mild to moderate intensity (severe TEAEs occurred in 6 patients in each treatment group). Most frequently reported TEAEs for perampanel $(\geq 10 \%)$ were dizziness, fatigue, headache, somnolence, and irritability (table 2). Serious TEAEs affected similar numbers of patients treated with placebo $(\mathrm{n}=7 ; 8.5 \%)$ and perampanel $(n=6 ; 7.4 \%$; table 3$)$. Most serious TEAEs were transient and manageable, but there were 2 deaths: one likely case of sudden unexpected death in epilepsy in the placebo group and one accidental drowning in the perampanel group. One patient receiving perampanel $6 \mathrm{mg} / \mathrm{d}$ experienced status epilepticus; the event was 


\begin{tabular}{|lll|}
\hline Table 2 & $\begin{array}{l}\text { TEAEs reported in } \geq 5 \% \text { of patients } \\
\text { treated with either placebo or } \\
\text { perampanel }\end{array}$ \\
\hline TEAE & $\begin{array}{l}\text { Placebo } \\
(\mathbf{n}=82)\end{array}$ & $\begin{array}{l}\text { Perampanel } \\
(\mathbf{n}=81)\end{array}$ \\
\hline Any TEAE & $59(72.0)$ & $67(82.7)$ \\
\hline Dizziness & $5(6.1)$ & $26(32.1)$ \\
Fatigue & $5(6.1)$ & $12(14.8)$ \\
Headache & $8(9.8)$ & $10(12.3)$ \\
Somnolence & $3(3.7)$ & $9(11.1)$ \\
Irritability & $2(2.4)$ & $9(11.1)$ \\
Nasopharyngitis & $7(8.5)$ & $7(8.6)$ \\
Vertigo & $2(2.4)$ & $7(8.6)$ \\
Vomiting & $2(2.4)$ & $7(8.6)$ \\
Weight increased & $3(3.7)$ & $6(7.4)$ \\
Contusion & $3(3.7)$ & $5(6.2)$ \\
\hline Nausea & $4(4.9)$ & $5(6.2)$ \\
\hline
\end{tabular}

Abbreviation: TEAE $=$ treatment-emergent adverse event. Data are $\mathrm{n}(\%)$.

classified as severe but resolved following discontinuation of perampanel. One patient in the placebo group also experienced status epilepticus, classified as moderate.

TEAEs necessitated discontinuation in 5 placebotreated patients (6.1\%) and 9 perampanel-treated patients (11.1\%). Of these, 3 placebo-treated patients (3.7\%) and 5 perampanel-treated patients $(6.2 \%)$ discontinued treatment following psychiatric disorders. For the 3 patients receiving placebo, these events included 2 mild to moderate cases of suicidal ideation and moderate cases of agitation, confusional state, and depression; for the 5 patients receiving perampanel, these events included one mild case of aggression, moderate cases of anxiety and insomnia, and severe cases of abnormal behavior, mood swings, suicidal ideation, and suicide attempt (patients with 2 or more AEs in the same system organ class [or with the same preferred term] are counted only once). Other TEAEs that led to discontinuation included 2 that affected more than one patient in the perampanel group: dizziness $(\mathrm{n}=2)$ and vomiting $(\mathrm{n}=2)$.

TEAEs necessitated dose adjustment or interruption in 6 placebo-treated patients $(7.3 \%)$ and 9 perampanel-treated patients $(11.1 \%[2 \mathrm{mg}, \mathrm{n}=1$; $6 \mathrm{mg}, \mathrm{n}=2 ; 8 \mathrm{mg}, \mathrm{n}=6])$. All of these TEAEs resolved (most without further action, although one case of nausea in the placebo group warranted treatment) except one case of dizziness in the perampanel group. One patient was withdrawn following interruption of perampanel treatment because of TEAEs of aggression and vomiting. The higher rates of dose adjustment or interruption in the perampanel group were attributed primarily to requirements for dose modification in patients with nervous system

\begin{tabular}{|c|c|c|c|c|c|c|c|}
\hline Table 3 & Serious TEAEs report & patients $\mathrm{tr}$ & ed with pla & o or peram & & & \\
\hline $\begin{array}{l}\text { Patient age, } \\
\text { y/sex }\end{array}$ & TEAE & Severity & $\begin{array}{l}\text { Day TEAE } \\
\text { started }\end{array}$ & $\begin{array}{l}\text { Day TEAE } \\
\text { resolved }\end{array}$ & $\begin{array}{l}\text { Relationship to study } \\
\text { drug }\end{array}$ & $\begin{array}{l}\text { Study drug action } \\
\text { taken }\end{array}$ & $\begin{array}{l}\text { Outcome at last } \\
\text { follow-up }\end{array}$ \\
\hline \multicolumn{8}{|l|}{ Placebo } \\
\hline \multirow[t]{2}{*}{$42 / M$} & Convulsion & Moderate & 12 & 12 & Not related & No dose change & Resolved \\
\hline & & & 15 & 20 & & & \\
\hline $25 / F$ & Fall & Moderate & 75 & 89 & Not related & No dose change & Resolved \\
\hline \multirow[t]{2}{*}{$35 / F$} & Grand mal convulsion & Mild & 40 & 40 & Possibly related & No dose change & Resolved \\
\hline & Grand mal convulsion & Moderate & 106 & 106 & Possibly related & No dose change & Resolved \\
\hline $46 / M$ & Nausea & Severe & 10 & 20 & Not related & Dose reduction & Resolved \\
\hline 21/M & Status epilepticus & Moderate & 31 & 34 & Not related & No dose change & Resolved \\
\hline $27 / F$ & SUDEP & Fatal & 11 & 11 & Not related & Drug withdrawal & Fatal \\
\hline 20/M & Thermal burn & Severe & 62 & Ongoing & Not related & No dose change & Resolving \\
\hline \multicolumn{8}{|l|}{ Perampanel } \\
\hline \multirow[t]{2}{*}{$22 / F$} & Chronic cholecystitis & Severe & 24 & 32 & Not related & No dose change & Resolved \\
\hline & Status epilepticus & Severe & 26 & 30 & Probably related & Drug withdrawal & Resolved \\
\hline $15 / F$ & Constipation & Moderate & 42 & 51 & Not related & No dose change & Resolved \\
\hline 29/M & Convulsion & Moderate & 117 & 119 & Not related & No dose change & Resolved \\
\hline 20/M & Drowning & Fatal & 64 & 64 & Not related & Drug withdrawal & Fatal \\
\hline $35 / F$ & Suicide attempt & Severe & 60 & 79 & Possibly related & Drug withdrawal & Resolved \\
\hline $30 / F$ & Suicidal ideation & Severe & 85 & 88 & Possibly related & Drug withdrawal & Resolved \\
\hline
\end{tabular}

Abbreviations: SUDEP = sudden unexpected death in epilepsy; TEAE = treatment-emergent adverse event. 
disorders, as defined according to the Medical Dictionary for Regulatory Activities (placebo $[\mathrm{n}=4]$ vs perampanel $[\mathrm{n}=8]$ ), or irritability (placebo $[\mathrm{n}=0]$ vs perampanel $[\mathrm{n}=3])$.

The following TEAEs of special interest affected more than $5 \%$ of perampanel-treated patients and were reported less frequently with placebo than perampanel: TEAEs related to alertness and cognition (narrow/broad SMQ terms: $14.6 \%$ vs $19.8 \%$ ), hostility/aggression (narrow/broad SMQ terms: $4.9 \%$ vs 18.5\%; narrow SMQ terms only: $0.0 \%$ vs $2.5 \%$ ), accident/injury (narrow/broad SMQ terms: 11.1\% vs $14.6 \%$ ), psychosis and psychotic disorders (narrow/broad SMQ terms: $3.7 \%$ vs $7.4 \%$; narrow SMQ terms only: $3.7 \%$ vs $3.7 \%$ ), and rash (narrow/broad SMQ terms: $1.2 \%$ vs $6.2 \%$ ). Other TEAEs of special interest were reported in $<5 \%$ of both treatment groups, with no TEAEs suggestive of abuse potential identified in either group.

There were no significant laboratory abnormalities. Mean increase in body weight was numerically lower for placebo $(+0.1 \mathrm{~kg})$ than for perampanel $(+1.8$ $\mathrm{kg})$. Three placebo-treated patients (3.7\%) had a body weight gain of $>7 \%$ at the end of treatment compared with 9 perampanel-treated patients $(11.1 \%$; only 2 cases of $>7 \%$ weight gain occurred in adolescents younger than 17 years, both in the perampanel group).

DISCUSSION Despite a perception that IGE and its associated seizures are easily treated, research suggests that approximately $35 \%$ to $40 \%$ of patients with some IGE syndromes (epilepsy with grand mal on awakening, juvenile myoclonic epilepsy, or childhood/juvenile absence epilepsy) may not achieve long-term seizure remission. ${ }^{15-19}$ Of all the seizure types associated with IGE, PGTC seizures are perhaps the most serious and a known risk factor for seizure-related injury and sudden unexpected death in epilepsy. ${ }^{20-25}$ However, a recent evidence review has supported the use of just 4 AEDs for the treatment of PGTC seizures (lamotrigine, levetiracetam, topiramate, and valproic acid), with evidence for zonisamide considered low-level. ${ }^{1}$ Of these, only lamotrigine, levetiracetam, and topiramate have demonstrated efficacy in randomized, doubleblind, placebo-controlled trials of adjunctive treatment for drug-resistant PGTC seizures. ${ }^{26-30}$ While methodologies varied, the size of the full analysis sets in these studies ranged from 45 to 164 patients, and median reductions in PGTC seizure frequency ranged from $-56.7 \%$ with topiramate (vs $9.0 \%$ with placebo; $p=0.019$ ) to $-77.6 \%$ with levetiracetam (vs $-44.6 \%$ with placebo; $p<0.001)$.

The present randomized, double-blind, placebocontrolled trial demonstrates the efficacy of adjunctive perampanel for the control of drug-resistant PGTC seizures in patients with IGE. The size of the full analysis set $(\mathrm{n}=162)$ and magnitude of the median reduction in PGTC seizure frequency $(-76.5 \%)$ compare favorably with previous studies of other AEDs. The PGTC seizure-freedom rate in the maintenance period (placebo [12.3\%] vs perampanel [30.9\%]) is also encouraging, given that the greatest reported PGTC seizure-freedom rate in such a setting is $34.2 \%$ with levetiracetam (vs placebo, $10.7 \%){ }^{26}$ These observations are particularly notable given that patients in the present study were experiencing PGTC seizures despite receiving up to 3 background AEDs, which commonly included those described above as recommended for the treatment of PGTC seizures (lamotrigine, levetiracetam, topiramate, and valproic acid). This may be indicative of more refractory epilepsy than in the previous studies, where patients were limited to 2 background AEDs.

To our knowledge, this study is novel in its use of external review of every enrolled patient to ensure enrollment of a pure population of patients with IGE, and to exclude patients with unclassified epilepsy or an uncertain diagnosis. This approach was supported by the independent review of each diagnosis by the Epilepsy Study Consortium. Notably, 70 of 307 patients submitted for enrollment by investigative sites were not approved by the Epilepsy Study Consortium either because they did not have IGE or there was insufficient information to confirm the diagnosis. In contrast, there was no standardization of IGE diagnoses between the different recruiting centers in the previous study of levetiracetam; 3- to $5-\mathrm{Hz}$ spike wave activity was seen in only 129 of 164 patients, and the diagnosis of IGE was "confirmed or suspected" in 158 of 164 patients. ${ }^{26}$ While other studies did not specify IGE as an inclusion criterion, evidence suggests the populations may not have been pure. In a study of lamotrigine ( $\mathrm{n}=117)$, many patients had a normal background EEG $(n=39)$ or were experiencing seizures not typically seen in IGE (tonic seizures $[n=11]$ or atonic seizures $[n=2]) .{ }^{28}$ In a study of topiramate $(n=80)$, again, many patients were experiencing seizures not typically seen in IGE (tonic seizures $[n=19]$ or atypical absence seizures $[n=6]) .{ }^{27}$

One important consideration for the treatment of seizures associated with IGE is the potential for improving control of PGTC seizures while exacerbating other seizure subtypes. ${ }^{31-33}$ While this study was not designed to evaluate the impact of perampanel on the frequency of myoclonic or absence seizure subtypes, and not all patients had a history of myoclonic or absence seizures (table 1), there was no evidence for exacerbation of these seizure subtypes.

Perampanel was well tolerated with no new or unexpected safety concerns. The TEAE profile was similar to that observed in previous phase III studies 
in patients with drug-resistant, partial-onset seizures, across which the most frequent AEs were dizziness, fatigue, headache, irritability, and somnolence, as reported here. ${ }^{9}$ Some AEs of special interest appeared more frequently with perampanel than placebo, including AEs relating to hostility/aggression, which is again consistent with the previous phase III data. Almost all TEAEs leading to dose reduction or interruption subsequently resolved, suggesting dosedependent effects. TEAEs necessitated discontinuation in 9 perampanel-treated patients $(11.1 \%$; vs placebo, $6.1 \%$ ), of whom 5 discontinued treatment following psychiatric disorders (6.2\%; vs placebo, 3.7\%).

While one study limitation may be the short treatment duration of only 17 weeks, patients had the option to subsequently receive adjunctive perampanel for 142 weeks in an open-label extension phase. This extension phase is currently ongoing, but it is anticipated that it will provide additional insight into the efficacy and safety of adjunctive perampanel for the treatment of drug-resistant PGTC seizures over a longer-term setting.

Overall, adjunctive perampanel $8 \mathrm{mg}$ was well tolerated and effective in improving seizure control in this randomized, double-blind, placebo-controlled, parallel-group study in patients aged 12 years and older with drug-resistant PGTC seizures in IGE. Taken together with previous data demonstrating efficacy in patients with partial-onset seizures, ${ }^{6-9}$ this indicates that perampanel can be considered a broadspectrum AED, which may be effective in both focaland generalized-onset seizures.

\section{AUTHOR CONTRIBUTIONS}

J.A.F.: contributed to data interpretation, prepared the outline and each draft of the manuscript, accepts accountability for all aspects of the work. G.L.K.: contributed to data interpretation, critically reviewed each draft of the manuscript, accepts accountability for all aspects of the work. R.T.W.: contributed to data interpretation, critically reviewed each draft of the manuscript, accepts accountability for all aspects of the work. X.-F.W.: contributed to data interpretation, critically reviewed each draft of the manuscript, accepts accountability for all aspects of the work. B.D.: contributed to data interpretation, critically reviewed each draft of the manuscript, accepts accountability for all aspects of the work. C.B.: contributed to data interpretation, critically reviewed each draft of the manuscript, accepts accountability for all aspects of the work. E.T.: contributed to data interpretation, critically reviewed each draft of the manuscript, accepts accountability for all aspects of the work. T.J.O.: contributed to data interpretation, critically reviewed each draft of the manuscript, accepts accountability for all aspects of the work. A.L.: contributed to data interpretation, critically reviewed each draft of the manuscript, accepts accountability for all aspects of the work. A.P.: conducted the statistical analyses, contributed to data interpretation, critically reviewed each draft of the manuscript, accepts accountability for all aspects of the work. F.B.: contributed to data interpretation, contributed to the development of the manuscript outline, critically reviewed each draft of the manuscript, accepts accountability for all aspects of the work.

\section{STUDY FUNDING}

The trial and analyses were funded by Eisai Inc. Editing of the manuscript, under the direction of the authors, was carried out by
Hannah FitzGibbon and Ann Gordon of Complete Medical Communications, funded by Eisai Inc.

\section{DISCLOSURE}

J. French is president of the Epilepsy Study Consortium, and the NYU Comprehensive Epilepsy Center and receives salary support from the consortium; has acted as a consultant for Acorda, Alexza, BioPharm Solutions, Biotie Therapies, Brabant Pharma, Eisai Medical Research, Georgia Regents University, GlaxoSmithKline, GW Pharmaceuticals, Marinus, Novartis, Pfizer, Pfizer-Neusentis, SK Life Science, Sunovion, Supernus Pharmaceuticals, Takeda, UCB/Schwarz Pharma, Ultragenyx, and Upsher-Smith (all consulting is done on behalf of the Epilepsy Study Consortium, and fees are paid to the consortium); has been an investigator for clinical trials funded by Acorda, Alexza, Eisai, LCGH, Novartis, Supernus Pharmaceuticals, Upsher-Smith, and Vertex; and has received grants from Eisai, Lundbeck, Pfizer, UCB, the Epilepsy Therapy Project, the Epilepsy Research Foundation, and the Epilepsy Study Consortium. G. Krauss has received personal compensation for serving on a safety board from Lundbeck and for consulting from Sunovion; and has received research support from Eisai, SK Life Science, Sunovion, UCB Pharma, and the NIH. R. Wechsler has received compensation for consulting and/or advisory boards and/or speaker bureau honoraria from $\mathrm{Cy}$ beronics, Eisai, Gerson Lehrman Group Inc., Lundbeck, Sunovion, UCB, and Upsher-Smith; serves as chair of the Corporate Advisory Committee; is a member of the Development Committee of the American Epilepsy Society and a member of the Epilepsy Study Consortium; and is a clinical trial investigator in trials sponsored by Alexza, Eisai, Lundbeck, Marinus, Pfizer, SK Life Science, Sunovion, UCB, UpsherSmith, and Vertex. X. Wang reports no disclosures relevant to the manuscript. B. DiVentura is an employee of the Epilepsy Study Consortium, which has received funding for research support and services provided from the following companies in the past year: Acorda, Alexza, BioPharm Solutions, Biotie Therapies, Brabant Pharma, Eisai Medical Research, Georgia Regents University, GlaxoSmithKline, GW Pharma Ltd., Marinus, Novartis, Pfizer, Pfizer-Neusentis, SK Life Science, Sunovion, Supernus Pharmaceuticals, Takeda, UCB Inc./Schwarz Pharma, Ultragenyx, and Upsher-Smith. C. Brandt has received personal compensation from Eisai, Otsuka, Pfizer, and UCB for serving on a scientific advisory board or for speaking activities or congress travel; his institution has received financial support for research activities from Otsuka and UCB. E. Trinka has acted as a paid consultant to Bial, Biogen, Eisai, EVER Neuro Pharma, Medtronics, Takeda, UCB, and Upsher-Smith; has received speakers honoraria from Bial, Boehringer, Eisai, GL Lannacher, and UCB Pharma; and has received research funding from Biogen, Merck, Novartis, Red Bull, UCB Pharma, the European Union, FWF (Österreichischer Fond zur Wissenschaftsförderung), and Bundesministerium für Wissenschaft und Forschung. T. O'Brien has received compensation for speaking at symposia from SciGen and UCB Pharma; and his institution has received funding for research from Eisai, Sanofi-Genzyme, SciGen, Janssen-Cilag, and UCB Pharma. A. Laurenza is an employee of Eisai Inc. A. Patten is an employee of Eisai Ltd. F. Bibbiani is an employee of Eisai Inc. Go to Neurology.org for full disclosures.

Received February 12, 2015. Accepted in final form May 21, 2015.

\section{REFERENCES}

1. Rheims S, Ryvlin P. Pharmacotherapy for tonic-clonic seizures. Expert Opin Pharmacother 2014;15:1417-1426.

2. Hanada T, Yang H, Ido K, Laurenza A. AMPA Receptor Antagonists for the Treatment of CNS Disorders: Antiepileptics and Beyond. Frontiers in Clinical Drug Research (Volume 3): CNS and Neurological Disorders. Sharjah, UAE: Bentham Science Publishers; 2015:34-76.

3. Durmuller N, Craggs M, Meldrum BS. The effect of the non-NMDA receptor antagonist GYKI 52466 and NBQX and the competitive NMDA receptor antagonist D-CPPene on the development of amygdala kindling and on amygdala-kindled seizures. Epilepsy Res 1994;17: $167-174$ 
4. Kodama M, Yamada N, Sato K, et al. Effects of YM90K, a selective AMPA receptor antagonist, on amygdala-kindling and long-term hippocampal potentiation in the rat. Eur J Pharmacol 1999;374:11-19.

5. Wu T, Nagaya Y, Hanada T. Pharmacodynamic and pharmacokinetic interactions of perampanel and other antiepileptic drugs in a rat amygdala kindling model. Seizure 2014;23:732-739.

6. French JA, Krauss GL, Biton V, et al. Adjunctive perampanel for refractory partial-onset seizures: randomized phase III study 304. Neurology 2012;79:589-596.

7. French JA, Krauss GL, Steinhoff BJ, et al. Evaluation of adjunctive perampanel in patients with refractory partialonset seizures: results of randomized global phase III study 305. Epilepsia 2013;54:117-125.

8. Krauss GL, Serratosa JM, Villanueva V, et al. Randomized phase III study 306: adjunctive perampanel for refractory partial-onset seizures. Neurology 2012;78:1408-1415.

9. Steinhoff BJ, Ben-Menachem E, Ryvlin P, et al. Efficacy and safety of adjunctive perampanel for the treatment of refractory partial seizures: a pooled analysis of three phase III studies. Epilepsia 2013;54:1481-1489.

10. European Medicines Agency. Fycompa summary of product characteristics. Available at: http://www.ema.europa.eu/docs/ en_GB/document_library/EPAR__Product_Information/ human/002434/WC500130815.pdf. Accessed August 7, 2015.

11. Food and Drug Administration. Fycompa prescribing information. Available at: http://www.accessdata.fda.gov/ drugsatfda_docs/label/2015/202834s005lbl.pdf. Accessed August 7, 2015.

12. Proposal for revised clinical and electroencephalographic classification of epileptic seizures. From the Commission on Classification and Terminology of the International League Against Epilepsy. Epilepsia 1981; 22:489-501.

13. Proposal for revised classification of epilepsies and epileptic syndromes. Commission on Classification and Terminology of the International League Against Epilepsy. Epilepsia 1989;30:389-399.

14. Berg AT, Millichap JJ. The 2010 revised classification of seizures and epilepsy. Continuum 2013;19:571-597.

15. Holtkamp M, Kowski AB, Merkle H, Janz D. Long-term outcome in epilepsy with grand mal on awakening: forty years of follow-up. Ann Neurol 2014;75:298-302.

16. Senf P, Schmitz B, Holtkamp M, Janz D. Prognosis of juvenile myoclonic epilepsy 45 years after onset: seizure outcome and predictors. Neurology 2013;81:2128-2133.

17. Trinka E, Baumgartner S, Unterberger I, et al. Long-term prognosis for childhood and juvenile absence epilepsy. J Neurol 2004;251:1235-1241.

18. Unterberger I, Trinka E, Luef G, Bauer G. Idiopathic generalized epilepsies with pure grand mal: clinical data and genetics. Epilepsy Res 2001;44:19-25.
19. Höfler J, Unterberger I, Dobesberger J, Kuchukhidze G, Walser G, Trinka E. Seizure outcome in 175 patients with juvenile myoclonic epilepsy: a long-term observational study. Epilepsy Res 2014;108:1817-1824.

20. Asadi-Pooya AA, Nikseresht A, Yaghoubi E, Nej M. Physical injuries in patients with epilepsy and their associated risk factors. Seizure 2012;21:165-168.

21. Hesdorffer DC, Tomson T, Benn E, et al. Combined analysis of risk factors for SUDEP. Epilepsia 2011;52: 1150-1159.

22. Hesdorffer DC, Tomson T, Benn E, et al. Do antiepileptic drugs or generalized tonic-clonic seizure frequency increase SUDEP risk? A combined analysis. Epilepsia 2012;53: 249-252.

23. Monte CP, Arends JB, Tan IY, Aldenkamp AP, Limburg M, de Krom MC. Sudden unexpected death in epilepsy patients: risk factors. A systematic review. Seizure 2007;16:1-7.

24. Tomson T, Beghi E, Sundqvist A, Johannessen SI. Medical risks in epilepsy: a review with focus on physical injuries, mortality, traffic accidents and their prevention. Epilepsy Res 2004;60:1-16.

25. Ryvlin P, Nashef L, Lhatoo SD, et al. Incidence and mechanisms of cardiorespiratory arrests in epilepsy monitoring units (MORTEMUS): a retrospective study. Lancet Neurol 2013;12:966-977.

26. Berkovic SF, Knowlton RC, Leroy RF, Schiemann J, Falter U. Placebo-controlled study of levetiracetam in idiopathic generalized epilepsy. Neurology 2007;69:1751-1760.

27. Biton V, Montouris GD, Ritter F, et al. A randomized, placebo-controlled study of topiramate in primary generalized tonic-clonic seizures. Topiramate YTC Study Group. Neurology 1999;52:1330-1337.

28. Biton V, Sackellares JC, Vuong A, Hammer AE, Barrett PS, Messenheimer JA. Double-blind, placebocontrolled study of lamotrigine in primary generalized tonic-clonic seizures. Neurology 2005;65:1737-1743.

29. Biton V, Di Memmo J, Shukla R, et al. Adjunctive lamotrigine $\mathrm{XR}$ for primary generalized tonic-clonic seizures in a randomized, placebo-controlled study. Epilepsy Behav 2010;19:352-358.

30. Trevathan E, Kerls SP, Hammer AE, Vuong A, Messenheimer JA. Lamotrigine adjunctive therapy among children and adolescents with primary generalized tonicclonic seizures. Pediatrics 2006;118:e371-e378.

31. Gelisse P, Genton P, Kuate C, Pesenti A, BaldyMoulinier M, Crespel A. Worsening of seizures by oxcarbazepine in juvenile idiopathic generalized epilepsies. Epilepsia 2004;45:1282-1286.

32. Genton P, Gelisse P, Thomas P, Dravet C. Do carbamazepine and phenytoin aggravate juvenile myoclonic epilepsy? Neurology 2000;55:1106-1109.

33. Thomas P, Valton L, Genton P. Absence and myoclonic status epilepticus precipitated by antiepileptic drugs in idiopathic generalized epilepsy. Brain 2006;129:1281-1292. 


\section{Neurology}

Perampanel for tonic-clonic seizures in idiopathic generalized epilepsy: A randomized trial

Jacqueline A. French, Gregory L. Krauss, Robert T. Wechsler, et al.

Neurology 2015;85;950-957 Published Online before print August 21, 2015

DOI 10.1212/WNL.0000000000001930

This information is current as of August 21, 2015

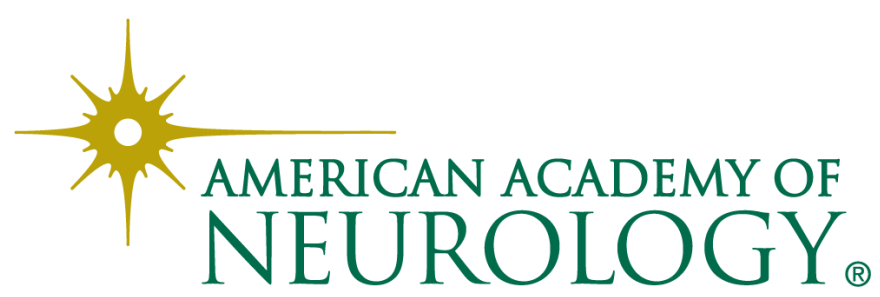




\section{Updated Information \& Services}

\section{Supplementary Material}

\section{References}

\section{Citations}

Subspecialty Collections

\section{Permissions \& Licensing}

\section{Reprints}

including high resolution figures, can be found at: http://n.neurology.org/content/85/11/950.full

Supplementary material can be found at: http://n.neurology.org/content/suppl/2015/08/21/WNL.0000000000001 930.DC1

http://n.neurology.org/content/suppl/2016/04/10/WNL.0000000000001 930.DC2

http://n.neurology.org/content/suppl/2016/04/10/WNL.0000000000001 930.DC3

This article cites 30 articles, 7 of which you can access for free at: http://n.neurology.org/content/85/11/950.full\#ref-list-1

This article has been cited by 5 HighWire-hosted articles: http://n.neurology.org/content/85/11/950.full\#\#otherarticles

This article, along with others on similar topics, appears in the following collection(s):

\section{Antiepileptic drugs}

http://n.neurology.org/cgi/collection/antiepileptic_drugs

Clinical trials Randomized controlled (CONSORT agreement)

http://n.neurology.org/cgi/collection/clinical_trials_randomized_control led_consort_agreement

Generalized seizures

http://n.neurology.org/cgi/collection/generalized_seizures

Information about reproducing this article in parts (figures,tables) or in its entirety can be found online at:

http://www.neurology.org/about/about_the_journal\#permissions

Information about ordering reprints can be found online:

http://n.neurology.org/subscribers/advertise

Neurology ${ }^{\circledR}$ is the official journal of the American Academy of Neurology. Published continuously since 1951, it is now a weekly with 48 issues per year. Copyright (C 2015 American Academy of Neurology. All rights reserved. Print ISSN: 0028-3878. Online ISSN: 1526-632X.

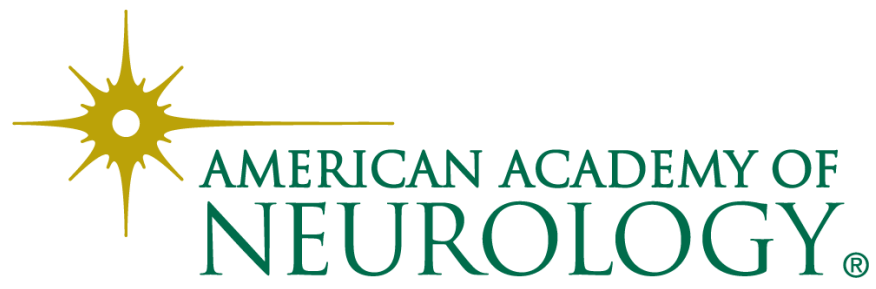

